\title{
EMERGENCY ONLINE LEARNING AT THE UNIVERSIDAD DE LA REPÚBLICA, URUGUAY: CHALLENGES FOR THE POST- PANDEMIC DIGITAL UNIVERSITY
}

Virginia Rodés-Paragarino, Gustavo García-Lutz, Universidad de la República, Uruguay

\section{Abstract}

Between 2005 and 2020, hybrid education at the Universidad de la República (Udelar), Uruguay, became universalized through the Virtual Learning Environments Program (ProEVA), with the aim of satisfying the growing demand for higher education, improving the quality of teaching, and reducing the digital and geographic gap. These developments were challenged during the implementation of emergency online learning arising from the COVID19 Pandemic. The article introduces preliminary analysis of this ongoing process, and the challenges they present for the digital transformation of the postpandemic university, and for the development of an appropriate, sovereign, critical digital pedagogy and caring approach for the Digital University.

Keywords: Emergency Online Learning, Digital University, Critical Digital Pedagogy, Pedagogy of Care, Post-Pandemic University

\section{Introduction}

Since March 13, the day the health emergency was declared in Uruguay, 2,097 positive cases of COVID-19 have been confirmed. Of that total, 1,824 have already recovered and 48 have died. Since that date, the Uruguayan population has followed the recommendations of the health authorities, voluntarily adopting social distancing, which has resulted in a successful management of the crisis

Since March 16, all face-to-face educational activities have been suspended, trying to respond to the emergency through the use of existing educational platforms. With a total population of 3,505,985 inhabitants, Uruguay has 148,056 tertiary-level students, of which 107,623 are university students. Of that total, the public sector covers $88 \%$ of enrolment with only two universities, one of which, the Universidad de la República (Udelar), comprises $99.4 \%$ of students. 
A very significant part of the growth of its student population, as well as the territorial expansion and academic offerings, occurred in the last ten years: four pre-university courses, 153 undergraduate courses, 311 postgraduate courses and five initial elective cycles. Its population is around 150,000 active students, 11,500 teachers and 6,300 technical administrative and service staff.

During the first semester all activity was developed through digital platforms. In the second semester, there has been a gradual return to some face-to-face activities, especially for clinical, assistance or laboratory practices. The rest remains in virtual formats.

\section{Pre-COVID 19 digital education in Udelar}

Between 2005 and 2020, hybrid education at the Udelar became universal through the Virtual Learning Environments Program (ProEVA), with the aim of satisfying the growing demand for higher education, improving the quality of teaching, and reducing the digital and geographic gap.

In 2008 started the activities of the nascent Project "Generalization of the use of ICT in Udelar" (TICUR Project), accompanied by a Technical Advisory Group (GTA), which in 2011 became the current ProEVA. First, the project, recognizing the restricted use of ICT in teaching practices at that time, promoted the strengthening of institutional capacities, the training of teachers and non-teachers and the creation of a Moodle based digital campus, which we now know as EVA. Most of the resources were invested in the training of teachers, trying to promote the design of learning situations. Hybrid learning combining face-to-face with blended learning or distance education. From one EVA, many EVAs evolved, according to the decentralized structure of the Udelar, being today one of the largest in the world in number of users $(334,661$ users among students, teachers and others).

Since 2013 an Open Education approach has been developed, and currently, the Digital Open Learning Ecosystem of ProEVA combines EVA with multiple educational platforms and services, developed with free software, that supports communities and individuals in the creation and use and reuse of digital content within the framework of open educational practices.

Until the end of 2019, most of the teaching teams used EVA as an additional and complementary educational resource to face-to-face teaching, although the development of hybrid educational practices, either with an expanded, blended, or distance classroom design, was beginning to become general in almost all the services. The starting point of students and teachers was heterogeneous in terms of their digital education experience, 
Rodés-Paragarino, V., \& García-Lutz, G.

Emergency Online Learning at the Universidad de la República, Uruguay: Challenges for the Post-

Pandemic Digital University

however, there was an accumulation of successful experiences and a network of Units of Teaching Support (UAEs), ProEVA Articulators and teaching teams with experience in design and teaching with digital technologies.

This scenario was characterized by universal access to EVA, according to preliminary results of the mandatory continuous survey for undergraduate students (Pérez \& Podetti, 2020 ), in which it is observed that $93 \%$ of undergraduate students had a user on EVA in 2019. For $56 \%$ of the students, EVA is the main source of educational resources for their study at Udelar and for $65 \%$ of them it has facilitated a better academic performance. $55 \%$ of undergraduate students considered themselves a frequent or very frequent user of the EVA. In those services in which the majority of students perceive that the EVA provides them with the best academic performance, it is in those services that it was being used most frequently. This distribution of the percentage of frequent or very frequent users was present in most of the Faculties between $70 \%$ and 79\%. Thus, it can be seen that the EVA and online teaching (such as an expanded classroom, blended or distance learning) already had a strong penetration and a high level of use and acceptance in almost all Udelar services.

\section{Responding to COVID-19: Emergency Online Learning}

As we already mentioned, the Udelar suspended face-to-face activities on March 16, establishing that teaching activities would be carried out through digital platforms for the rest of the first semester of 2020. It also ensured that all students could follow the courses through the established modalities, distributing scholarships to ensure access to connectivity as well as computers for those who did not have their own. The formats adopted were both synchronous and asynchronous. From the first day of emergency remote teaching, and with the aim of accommodating large groups (more than 500 students) and allowing teachers to continue their synchronous lectures, it was decided to incorporate a number of commercial solutions such as ZOOM and Webex, in addition of ProEVA's Open Digital Ecosystem.

Among the first measures to address the emergency, on March 16th ProEVA delivered its Contingency Plan (Educational Sectoral Commission, 2020), based on an approach focused on caring for the entire university community and its resources, defining the actions as online teaching and learning in emergency conditions. The work proposal, based on a pedagogy of care, seeks to address the diversity and vulnerability to which, as individuals and as an educational community, we are exposed to the emergency situation. Addressing these highly complex problems, this framework integrates the perspective of an ethic of care (Barnes, Brannelly, Ward, \& Ward, 2015) as a fundamental dimension of teaching practice (Noddings, 2013; Adams \& Rose, 2014) and the consideration of the teaching as 
Rodés-Paragarino, V., \& García-Lutz, G.

Emergency Online Learning at the Universidad de la República, Uruguay: Challenges for the PostPandemic Digital University

an experience of care. In this way, the Contingency Plan was aimed at generating proposals that consider the moment that society is going through, seeing and recognizing itself as subjects, developing online learning processes with simplicity, commitment and empathy, deepening human contact. On the other hand, the perspective of care extends to technological resources, in whose selection is promoted a rigorous analysis that includes an ethical and digital rights perspective, prioritizing the use of free software and open formats, as well as privacy and data management of user personal data, avoiding those that require students to create accounts. For this, the Udelar already had a digital learning ecosystem, a support and consultation community and a series of open courses for training and / or reuse.

An analysis of the 184 graduate degrees at Udelar (Collazo and Cabrera, 2020) showed that the change to the virtual modality reached 2,720 courses in virtual modality during the first semester of this year, leaving 120 without being lectured because they are practical, workshops or clinics. It is observed that $73 \%$ of the curricular units were developed completely in virtual formats, $23 \%$ had done so partially, while $4 \%$ had not been able to offer them and had been postponed. In June 2020, 24,000 virtual classes were held through web conference platforms.

During the first semester of 2020, the study of the increase in EVA activity (Pérez \& Podetti, 2020 ) showed an increase of $20 \%$ in the number of users. This increase is greater in those services in which users declared in 2019, that did not use the EVA frequently. Regarding the percentage variation in the number of courses, it was found that the sum of courses registered in the EVA increased by $28 \%$, with notable differences between Faculties. Those in the Area of Technologies and Sciences of Nature and Habitat showed a growth in the number of courses greater than 50\%, while those in the Social and Artistic Area, showed less than $14 \%$, being higher in those Faculties that had registered users with no intensive use.

The most significant and explanatory variation of the changes produced during the past semester is expressed in the increase of two indicators of use that the Moodle statistics show: messages (communication) and questionnaires (evaluation, self-evaluation). According to the report, the number of messages sent through the EVA Forums increased by $149 \%$. The Services that indicate a growth of over $450 \%$ are the Faculty of Psychology and the Faculty of Architecture and Design. The rate of messages per user in those Faculties that have the highest growth rate, is what indicates that they processed a change in the use of the EVA, consolidating itself as a means of educational communication. The highest rates of messages per user are presented by the Faculty of Chemistry (11.1), the School of Nutrition and Dietetics (10.9), the Faculty of Nursing (9.4) and the Faculty of 
Rodés-Paragarino, V., \& García-Lutz, G.

Emergency Online Learning at the Universidad de la República, Uruguay: Challenges for the Post-

Pandemic Digital University

Engineering $(8,8)$, with the average number of messages per user among the EVAs of 5.1. The evolution of the use of the EVA as a repository to support face-to-face teaching as a Distance Education tool is seen in the rate of increase and in the number of questions registered in the EVA question banks. This is an indicator of the increasing use of EVA as an evaluation and interactivity instrument. The EVA of the Faculty of Medicine (622\%), the Central EVA - mainly composed of the regional university centres - (452\%), and the Faculty of Architecture (353\%) showed the highest growth rate. The services with the least increase also doubled the number of existing questions.

From the study of the evaluation that students make of the educational proposal carried out by Udelar in the month of July (DGPlan, 2020), it is highlighted that of the 99,839 students enrolled in courses during the first semester of 2020,85\% indicated having taken courses under the virtual modality, as a result of the change of modality (DGPlan, 2020), and of these, more than 84.000 students, almost 92\%, managed to finish any of these courses under the new modality, which is equivalent to about approximately 77,500 students. The student evaluation of this educational proposal for the semester in virtual mode reflects a favourable level of satisfaction of 56\% (they stated they were satisfied or very satisfied with the implementation of the new modality). $20 \%$ say they are dissatisfied or very dissatisfied. Emotional involvement and overload of teaching activities were the difficulties with the highest mention in $66 \%$ and $50 \%$ respectively.

\section{Building the Post-COVID19 Digital University}

The potential impacts of this transformation operated by the so-called "great onlining" (Brown, Costello, \& Giolla Mhichíl, 2020), generate concern regarding the way these remote teaching experiences in emergencies lead to uncritical and dubious quality models that affect negatively the current scenario of Higher Education, influencing the digital transformation of the universities that was already being processed.

The University is threatened by the neoliberal model, which treats digital technology as a market server, and students as clients (Johnston, MacNeill, \& Smyth, 2018). Added to this, is the deepening of so-called platform capitalism (Srnicel, 2017) accelerating the process of colonization of education by large corporations (Google, Apple, Facebook, Microsoft and Amazon, among others).

Within this framework, university teaching teams need institutional support and teaching professional development strategies to face this enormous challenge, in order to mitigate the potential effects on the quality of education, and to favour that this massive and emergency experience allow to lay the foundations of a digital university model based on appropriate, sovereign and critical developments and social justice. This becomes even 
Rodés-Paragarino, V., \& García-Lutz, G.

Emergency Online Learning at the Universidad de la República, Uruguay: Challenges for the Post-

Pandemic Digital University

more necessary in the case of public Latin American universities, especially focused on guaranteeing educational continuity in political, social and economic settings characterized by inequity and exclusion, privatization of education and technological infrastructures.

An appropriate, sovereign and critical approach implies addressing digital literacy and the transformation of the curriculum, as key dimensions of the digital university committed to social justice (Johnston et al., 2018). In this approach, the critical digital pedagogical perspective constitutes a central emancipatory element, supporting the redesign of technological spaces and environments for teaching and learning from a radical understanding of digital, pedagogical and social relationships, expanding the possibilities of democratization.

The development of a powerful public education with universal coverage of higher education, conceived as a human right, favours the continuity of access to education in emergencies such as the current one. The development of powerful infrastructures based on public investment favours the conditions for universal access to the internet, and educational technology policies that provide open, free and sovereign solutions that support autonomy in the face of potential market problems in an emergency.

This institutional framework, a framework of teaching potential and open infrastructure, allowed Udelar to give a response according to the circumstances to carry out the emergency non-face-to-face teaching imposed by the pandemic. This response was not homogeneous, because the Udelar is not homogeneous. It was a reflection of the different paths that the different Faculties and university centres were experiencing from that distant 2008 until now. Those services that, from their UAE (teaching support units), promoted the training of teachers and strengthened their EVA were without any doubt, in better conditions than those that did not. Those teachers who understood what their role was in the University of the $21^{\text {st }}$ century and were taking advantage of the different free training instances offered centrally by ProEVA or by the UAE of its services, were in better conditions to face this challenge, than one day to the other had to be faced.

The nature of the response does not, and never, depended on the EVA as a tool, but on the didactic design that was carried out for its use. But we can say that in most cases the response fulfilled the expectations of users, that is, university students, the ultimate recipients of these efforts. We especially want to highlight this last aspect. Distance Education taught by universities dedicated especially to this model, is based on a highly thought-out pedagogical design that is the result of an experience of several decades, in which everything is thought out, from teaching practices to evaluation, to be done 
Rodés-Paragarino, V., \& García-Lutz, G.

Emergency Online Learning at the Universidad de la República, Uruguay: Challenges for the Post-

Pandemic Digital University

remotely. It is not the product of any emergency. That is the big difference and it makes both modalities not comparable.

Already in the 2010 external evaluation report of TICUR, the commission of intentional experts said that it was "an ambitious project in its purposes, since together with objectives of deepening the principle of equal opportunities or decisions on the convenience of the decentralization of the Udelar, it is intended to take on the challenges of the renewal of teaching methodologies through the incorporation of ICT". Today, ten years after this report, we see how, with the technical-pedagogical leadership of ProEVA, and the network in services, these objectives have largely been achieved. Without the EVA this response to the emergency would not have been possible. With EVA, the Udelar will surely continue to advance in its democratizing objectives, in equal opportunities and deepening from a methodological renewal. A challenge to strengthen it, and generalize its good use.

The "Proposal for the country 2020-2024. Strategic development plan of the Universidad de la República" represents a road map for the redefinition, expansion and hierarchisation of work lines that ProEVA has been developing for 12 years.

On the one hand, it implies the reformulation and updating of the Virtual Learning Environments Program to the challenges of deepening the virtualization processes of university education in hybrid modalities, as well as evaluating its consolidation in complete academic programs in blended or distance modality. This presents important academic, governance, and human and material resources challenges to become a quality proposal.

On the other hand, there is the challenge of matching these processes with the development of institutional capacities that: (a) allow students and teachers to have sufficient digital skills to teach, learn and exercise citizenship in a highly digitized society; (b) expand the teaching appropriation of specific technologies and articulated to the specific didactics of the disciplinary fields, integrated into educational research and the training of highly qualified human resources in the field of educational technology; (c) take advantage of the information available in the various academic management systems and educational platforms, to better understand their impact on student's educational trajectories, and the development of early warning systems for educational disengagement.

\section{References}

Adams, C., \& Rose, E. (2014). Will I ever connect with the students? Online Teaching and the Pedagogy of Care. Phenomenology \& Practice, 8(1), 5-16.

https://doi.org/10.29173/pandpr20637 
Rodés-Paragarino, V., \& García-Lutz, G.

Emergency Online Learning at the Universidad de la República, Uruguay: Challenges for the Post-

Pandemic Digital University

Barnes, M., Brannelly, T., Ward, L., \& Ward, N. (Eds.) (2015). Ethics of care: Critical advances in international perspective. Bristol: Bristol University Press. doi:10.2307/j.ctt1t89d95

Brown, M., Costello, E., \& Giolla Mhichíl, M. N. (2020). Responding to Covid-19: The Good, the Bad and the Ugly of Teaching Online. International Council for Open and Distance Education. Retrieved from https://www.icde.org/icdeblog/2020/3/26/responding-to-covid-19

Comisión Sectorial de Enseñanza. (2020a, March 16). Plan de Contingencia del Programa de Entornos Virtuales de Aprendizaje (EVA) de la Udelar - Universidad de la República I Covid 19. Retrieved from https://coronavirus.udelar.edu.uy/plan-decontingencia-del-programa-de-entornos-virtuales-de-aprendizaje-de-la-udelar/

Collazo, M., \& Cabrera, C. (2020). Primeros resultados Encuesta Coordinadores de Carreras Situación de la Enseñanza en Línea. Unidad Académica, Comisión Sectorial de Enseñanza, Universidad de la República. Retrieved from https://www.cse.udelar.edu.uy/wp-content/uploads/2020/08/EnsenanzaEnLineaEncuesta.pdf

Dirección General de Planeamiento, DGPlan, Universidad de la República. (2020). Principales resultados de la Encuesta a estudiantes de la Udelar para la evaluación de la propuesta educativa en la modalidad virtual del primer semestre 2020. Retrieved from https://udelar.edu.uy/portal/wpcontent/uploads/sites/48/2020/07/Resumen_Difusi\%C3\%B3n_Informe_encuestaestudiantes.pdf

Johnston, B., MacNeill, S., \& Smyth, K. (2018). Conceptualising the digital university: The intersection of policy, pedagogy and practice. Palgrave Macmillan, Inglaterra.

Noddings, N. (2013). Caring: A Relational Approach to Ethics and Moral Education. University of California Press.

Pérez Casas, A., \& Podetti, M. (2020). Programa Entornos Virtuales de Aprendizaje, Comisión Sectorial de Enseñanza, Universidad de la República (2020). Informe: Incremento en el número de usuarios y actividad en el EVA durante la emergencia de COVID19. Primer Semestre 2020. Montevideo, Uruguay.

Srnicek, N. (2017). The challenges of platform capitalism: Understanding the logic of a new business model. Juncture, 23(4), 254-257.

Universidad de la República (2020). Propuesta al país 2020-2024. Plan estratégico de desarrollo de la Universidad de la República. Ediciones Universitarias. 